\title{
The Research Library Director's View of Library Education
}

\begin{abstract}
Opinions of directors of the Association of Research Libraries (ARL) member libraries concerning nineteen competencies were analyzed regarding (1) their importance now and in five years, (2) their need in different positions, (3) their possession by beginning librarians, and (4) adequacy of instruction in library schools. Respondents felt that (1) competency levels need to increase, especially in analytical, statistical, research, and computer-technology skills, (2) the preparation for traditional librarian roles is not appropriate for system/computer specialists, and (3) less than half of their entry-level librarians come to their jobs satisfactorily trained.
\end{abstract}

\begin{abstract}
A T THE OCTOBER 15-16, 1980, meeting of the Association of Research Libraries, the Task Force on Library Education, chaired by Margot B. McBurney of Queens University, Kingston, Canada, distributed accumulated data derived from questionnaires returned by 76 of 111 ARL library directors queried regarding education for research librarians.
\end{abstract}

The study concerned the educational needs of entry-level librarians. It asked several questions; each concerning nineteen competency areas. For each, respondents were asked: (1) the extent to which the competencies are required now and will be required in five years, (2) which of six different position categories require the various competencies, (3) the extent to which they are now possessed at a satisfactory level by beginning librarians, (4) where (or by what process) they are being and should be acquired, and (5) the methods of staff development currently used to improve staff. Unfortunately, the data were not analyzed in depth. Frequency distribution tables were passed out. A brief summary was presented with a short discussion following. ${ }^{1} \mathrm{~A}$ belief that the cumulated opinions of the most im-

Maurice P. Marchant is professor and Nathan $M$. Smith is director, School of Library and Information Sciences, Brigham Young University, Provo, Utah. portant research library administrators in the United States and Canada might be useful to library educators resulted in the following analysis. We believe that an independent appraisal from outside ARL is appropriate, and that it might result in insights both supporting and conflicting with those of a committee of administrators.

The data's weaknesses need to be explicated. (1) Directors do not often choose or supervise newly hired professionals directly, so their perception of the level of the various competencies required within their own libraries may not be accurate. Some directors may have consulted with other staff administrators in order to provide the best possible responses, but others might simply have given the best answers they individually had, even as they recognized that their appraisals might be inaccurate. (2) One-third of the directors did not respond. The extent to which their responses might be reflected in the data collected is unknown. One might theorize that those who care the most about educational preparation of their professional staffs were more likely to respond. (3) The responses are opinions, and they can be expected to deviate from the actual competency needs in their libraries. Educators will also vary regarding the extent to which they believe library schools should match the education they provide to the profile of expectations of administrative practitioners. 


\section{Areas of Competency}

Before analyzing the data, the areas of competency will be listed and discussed briefly. Nineteen were included. The report called them "skills," but as they clearly include knowledge as well, the more generic term competency is used throughout this report.

1. Research skills.

2. Knowledge of a foreign language.

3. In-depth knowledge of an academic subject.

4. Statistical skills.

5. System analysis skills.

6. Computer programming skills.

7. Online retrieval skills.

8. Knowledge of general bibliography.

9. Knowledge of general reference materials.

10. Knowledge of specialized reference materials.

11. Knowledge of theories of organizing information. tion.

12. Basic knowledge of library automa-

13. Knowledge of collection development theories and practices.

14. Knowledge of library history.

15. Knowledge of library issues.

16. Human relations skills.

17. Supervisory skills.

18. Managerial skills.

19. Analytical skills.

Cataloging and classification skills are not included in the list. Presumably, they are intended for inclusion under knowledge of theories of organizing information even though knowledge of theory does not assure skillful application. Also missing is knowledge of library philosophy. Other than these two omissions, the major issues of librarianship seem adequately covered.

Research skills mean more than literature search skills, but some respondents may not have viewed them thusly. Statistical, system analysis, and analytical skills are all useful in research.

McBurney observed that the nineteen competencies cover three areas. "The first seven skills listed include some of the newer or more nontraditional skills which have become significant in libraries, often considered the tools of the library specialist. . . .
The next eight skills are the substance of the basic, traditional library school curriculum. . . . The last four skills are what I consider to be 'people' skills or, in the broadest sense, the managerial skills."

\section{COMPETENCIES NEEDED BY \\ ENTRY-LEVEL LiBRARIANS, Now AND IN Frve Years}

Asked to check the needs of entry-level librarians, now and in five years, respondents had their choice of six need levels:

1 = required for many positions

2 = highly desirable for many positions

3 = the most important skill for some specialist positions

$4=$ needed as background for most positions

$5=$ not important at entry level

$6=$ not needed.

These levels can be thought of as being somewhat related one to another: that is, they are in order of importance, but the distance between them may not be of the same magnitude. Nonetheless, they lend themselves to the computation of means, which can then be arranged, as we have done in table 1 , to indicate relative importance given to the various competencies. The means are given for importance now and in five years but arranged by "now" means. Slight differences should not be given much attention. Note that the lower the number, in table 1 , the greater the importance.

Knowledge of general reference and general bibliography are considered required by most respondents. These traditional competencies are followed by several highly desirable competencies, some of which are relatively new to library education. They include human relations skills, analytical skills, library automation, and online retrieval skills.

At the bottom of the rankings are two very different competencies: computer programming skills and knowledge of library history. Their mean values suggest that they are useful as background for most positions. While that may be correct for library history, computer programming clearly falls in category three, important for some specialties.

The mean values described quite well the average importance given to twelve of the 
TABLE 1

Importance Now and in Five Years of LibRaRy Competencies

\begin{tabular}{|c|c|c|}
\hline & Now & $\begin{array}{l}\text { In Five } \\
\text { Years }\end{array}$ \\
\hline \multicolumn{3}{|l|}{ Required of many positions } \\
\hline 1. Knowledge of general reference & 1.47 & 1.57 \\
\hline 2. Knowledge of general bibliography & 1.48 & 1.70 \\
\hline \multicolumn{3}{|l|}{ Highly desirable for many positions } \\
\hline 3. Human relations skills & 1.76 & 1.69 \\
\hline 4. Analytical skills & 1.84 & 1.82 \\
\hline 5. Knowledge of a foreign language & 1.92 & 1.89 \\
\hline 6. Basic knowledge of library automation & 2.08 & 1.78 \\
\hline 7. Online retrieval skills & 2.40 & 1.90 \\
\hline 8. Knowledge of specialized reference materials & 2.46 & 2.25 \\
\hline 9. Knowledge of theories of organizing information & 2.47 & 2.19 \\
\hline \multicolumn{3}{|l|}{ Most important skills for some specialist positions } \\
\hline 10. Research skills & 2.51 & 2.17 \\
\hline 11. In-depth knowledge of an academic subject & 2.58 & 2.27 \\
\hline 12. Knowledge of library issues* & 2.61 & 2.47 \\
\hline 13. Knowledge of collection development theories and practices & 2.62 & 2.41 \\
\hline 14. Supervisory skills* & 2.83 & 2.70 \\
\hline 15. Managerial skills* & 3.19 & 2.93 \\
\hline 16. Statistical skills* & 3.21 & 3.08 \\
\hline 17. System analysis skills $\uparrow$ & 3.49 & 3.05 \\
\hline \multicolumn{3}{|l|}{ Needed as background for most positions } \\
\hline 18. Knowledge of library history* & 4.03 & 3.90 \\
\hline 19. Computer programming skills $\uparrow$ & 4.30 & 4.05 \\
\hline Importance of average competency & 2.59 & 2.41 \\
\hline
\end{tabular}

-Judgments were bimodally distributed, peaking at values 2 and 5 .

tJudgments were bimodally distributed, peaking at values 3 and 5 .

top thirteen competencies (all but knowledge of library issues). But the bottom six (items 14 to 19) plus library issues (item 12) had bimodal distributions that reduce the usefulness of their average values considerably.* Two related competencies were knowledge of library issues and library history. They peaked at values 2 and 5 . Few respondents thought of knowledge of library issues or library history as valuable background information. Rather, they scored them as either highly desirable or not important. The dichotomy is similar but with higher peaks regarding statistical, supervisory, and managerial skills. The importance of system analysis and computer programming skills also distributed bimodally, but peaked on values 3 and 5 . McBurney wondered if these contrasting judgments resulted from differences in needs between larger and smaller research libraries. ${ }^{3}$ To us, the bimodal distributions suggest a division of ARL directors

*The data from which these bimodal distributions were observed were provided by the ARL Task Force on Library Education. We have not reproduced them here, since we view our role as evaluating the data. Those wishing to examine the data directly might contact ARL for copies. into a group of traditionally oriented administrators concerned with history and humanistic scholarship and another group that is concerned with modernizing library operations.

The data regarding the four managerial skills were interpreted by McBurney as showing them to be either required or highly desirable. She also observed that one-third to one-half of the respondents considered supervisory and managerial skills not important at the entry level. ${ }^{4}$ This disagreement led to the low ranking of these two skills.

ARL directors apparently expect the need for competency to increase in importance in the next five years, since the average competency rose from 2.59 to 2.41 . Only two declined at all. The one with the greatest drop is knowledge of general bibliography, and it declined by 0.22 . By contrast, eight increased by at least that much. The increases are not equally distributed, and some competencies are thought to be increasing in importance more rapidly than others. The greatest gains are desired in the areas of (1) online retrieval skills, (2) system analysis skills, (3) research skills, (4) in-depth knowledge of an academic subject, and (5) basic 
knowledge of library automation. These observations support the evolution in library curriculum toward information science and technology, and it recommends that greater attention be given to teaching research skills. Surprisingly, however, neither analytical nor statistical skills emerged as needing much increased attention.

McBurney, by contrast, interpreted the data as calling for the greatest changes in the areas of (1) in-depth subject knowledge, (2) basic knowledge of library automation, and (3) human relations. ${ }^{5}$ We agree regarding the first two, but find no evidence in the data regarding human relations, which already is ranked high in importance. She did not mention online retrieval, system analysis, or research skills, which showed the greatest increases in our computations.

\section{COMPETENCIES NEEDED FOR Different Positions}

Administrators were asked to check off the competencies which should be taught in preparation for six different positions that are filled by entry-level librarians. The positions are (1) original cataloging, (2) general reference, (3) subject reference, (4) collection development, (5) supervision of a department library, and (6) systems/computer services. Respondents could check as many positions as they felt appropriate for a given competency. The mean number of tallies given to the average position for the average competency was 35.4 . The number of tallies varied from a low of two (computer programming skills needed for positions in collection development and supervision of departmental library) to a high of seventy-two (knowledge of general reference materials needed for general reference positions).

These data serve as a rough indicator of the course work expected of entry-level librarians applying for various positions. Listed below, under each position title, are the five competencies viewed by the largest number of directors as important for that position, the number in parentheses indicating the number of directors.

\section{Original cataloger}

Knowledge of general bibliography (62)

Basic knowledge of library automation (61)
Knowledge of theories of organizing information (59)

Knowledge of a foreign language (53)

Analytical skills (47)

General reference

Knowledge of general reference materials (72)

Knowledge of general bibliography (71)

Human relations skills (61)

Online retrieval skills (60)

Knowledge of theories of organizing information (59)

Subject reference

Knowledge of specialized reference materials (70)

Knowledge of general bibliography (65)

Knowledge of general reference materials (65)

Online retrieval skills (63)

Research skills (60)

Collection development

Knowledge of general bibliography (66)

Knowledge of general reference materials (57)

Knowledge of collection development theories and practices (57)

Knowledge of specialized reference materials (55)

Research skills (54)

Supervisor of department library

Human relations skills (38)

Supervisory skills (36)

Knowledge of general reference materials (36)

Managerial skills (35)

Basic knowledge of library automation (34)

Systems/Computer services

System analysis skills (53)

Basic knowledge of library automation (52)

Computer programming skills (49)

Statistical skills (47)

Analytical skills (45)

Pearson product-moment correlation coefficients were computed between each of the six categories and are presented in table 2.

Preparation expected for the first four positions is very similar. Subject reference librarians seem to require the greatest preparation, followed closely by general reference librarians. The competencies expected of de- 
TABLE 2

Intercorrelations Between Educational Preparation ExPected for Six Library Position Categories

\begin{tabular}{lrrrrr}
\hline \hline & 1 & 2 & 3 & 4 & 5 \\
\hline Original cataloger & & & & & \\
General reference & .85 & & & & \\
Subject reference & .76 & .94 & & \\
Collection development & .73 & .89 & .93 & .60 & \\
Supervisor/dept. library & .55 & .64 & .64 &. .48 & -.31 \\
Systems/computer service & -.12 & -.24 & -.41 & -.48 \\
\hline
\end{tabular}

partmental library supervisors ranked in much the same order, but at a much lower level of expectation.

Preparation for systems/computer services varied from the common pattern, as might be expected. The low and negative values relating systems/computer service expectations with the other position categories suggests that preparation for traditional library positions is not appropriate for this one. The competencies emphasized for this job are only marginally important in the others, and competencies expected for the traditional positions are thought to be of low importance in this one. Possibly the respondents were not adequately aware of the informational needs of people in this job category: that is, their need for knowledge of bibliographical and reference materials might be greater than the directors realize. But if the directors are correct, library educators should give serious consideration to structuring a degree program specifically for systems/computer service specialists.

As a check on the directors' judgments, we queried the heads of systems/computer services in ARL libraries. The same set of competencies were listed in the same order, and the respondents were asked to check as many as they felt should be taught to librarians for entry-level positions in systems/computer services. Of 111 questionnaires distributed, 74 were returned and 70 were usable.

Whereas the average director checked 7.1 competencies, the average system/computer head checked 9.7 competencies. If the system/computer heads are the more correct group, as might be assumed from their more intimate involvement in this type of work, the data show that the directors underestimate by an average of 2.6 (or 27 percent) the number of competency areas needed by this category of beginners. But the ranking of competencies by importance, as measured by the number of checks received, is very similar for the two groups, the correlation coefficient for the pairs of data being 0.95 . While the disagreement is fairly slight, compared to the systems/computer heads, the directors overstated the need for programming skills and knowledge of library history and understated the need among systems/computer specialists for human relations and analytical skills.

\section{SKILLS PosSESSEd BY \\ ENTRY-LEVEL LiBRARIANS}

Question four asked the survey respondents to rate entry-level librarians in four categories:

1. Most possess the skill to a satisfactory degree

2. About one-half possess the skill to a satisfactory degree

3. Few possess the skill to a satisfactory degree

4. Almost none possess the skill to a satisfactory degree

Considering these four categories as intervals, using the 1 to 4 ratings above, a mean score was calculated for each competency. Table 3 ranks possession of the competencies from most to least satisfactory among entrylevel librarians.

The directors rated only two competencies, knowledge of general reference materials and general bibliography, as possessed at a satisfactory level. All the rest were held satisfactorily by no more than half of the current entry-level librarians. Starting with knowledge of specialized reference materials, ARL directors felt that nine competencies were satisfactorily possessed by only about one-half of beginning librarians. Beginning with twelfth-ranked collection development skills, the directors indicated only a few entry-level librarians possessed eight 
TABLE 3

Competency Possession by Entry-Level Librarians

Competency

Most possess skill to a satisfactory degree (1.00-1.49)

1. General reference materials

2. General bibliography

About $1 / 2$ possess skill to a satisfactory degree (1.50-2.49)

3. Specialized reference materials

4. Foreign language

5. Library issues

6. Library history

7. Library automa

8. Theories of organizing information

9. Subject knowledge

2.14

10. Human relations skills

11. Online retrieval skills

Few possess skill to a satisfactory degree (2.50-3.49)

12. Collection development

13. Research skills

14. Analytical skills

15. Supervisory skills

2.62

16. Managerial skills

17. Statistical skills

3.34

18. System analysis skills

19. Computer programming skills

3.49

competencies at a satisfactory level; and forty-eight, thirty-four, and thirty-eight respondents said that almost none satisfactorily possessed the last three on the list (statistical, system analysis, and computer programming skills).

We question whether the administrators responded accurately to this survey question. For example, consider whether all new librarians need to know computer programming, a very specialized skill. It seems more reasonable to expect those few librarians who are hired to program will have a knowledge of computer programming. Suppose a library has 4 positions requiring programming skills among a professional staff of 100 . Even that number seems quite high. If all 4 or even 3 had been properly screened when they were hired to assure they could program, the director should have reported that most possess this skill to a satisfactory degree. But only six directors said so, suggesting that they are either hiring incompetent programmers or, more likely, they were reporting the extent to which their professional staff in general can program without regard to need. Take another example. In their response to question three, they indicated that few beginning librarians need supervisory or managerial skills. Now we are being told that even among these few, only a small number pos- sess them. Again, we suspect that they intended to say simply that few beginning librarians have these skills without regard to their immediate need for them. If this interpretation of respondent intent is correct, the rankings indicate the respondents' perception of new librarians' skills without regard to need.

We note that competencies traditionally part of library school curricula tend to rank high whereas recent introductions, such as online retrieval, human relations, and statistical skills, are further down. Does this mean that library schools are considered to have added important new components but are not teaching them very well? We do not know.

McBurney's analysis of satisfactory skill attainment agrees with ours, but she sheds no light on her committee's interpretation of what satisfactory attainment means. ${ }^{6}$

\section{Where Skills Are ACQuired AND Where Directors Think \\ They SHOUld BE ACQuired}

Asked to check where the competencies of entry-level librarians are acquired and where they thought they should be acquired, respondents had their choice of ten categories:

1. In library school 
2. In another academic program before hiring

3. In previous library work experience

4. In previous nonlibrary work experience

5. In formal course work, after hiring

6. On the job

7. At special institutes, conferences, etc., after hiring

8. Through professional activities (e.g., committees)

9. In an internship program

10. Other (e.g., independent study)

Respondents could check as many of the above categories for each competency as they felt applied. The maximum number of checks for any category was seventy-six. In this section we have limited our analysis of the results to category 1 , in library school. Results of the analysis are listed in table 4. The data are ranked according to the difference between the number of directors who thought the skills should be acquired in library school and those who thought the skills are acquired in library school.

In every case, more ARL directors felt the competency should be taught in library school than is now occurring, but the unmet differential varies considerably. A small unmet differential is interpreted as meaning that library schools are meeting the expecta- tion of administrators. Most of them are satisfied with library school instruction in library history, specialized reference materials, general bibliography, and general reference materials. They do not expect library schools to provide instruction in foreign languages or academic subjects.

On the other hand, library schools are disappointing large numbers, more than half, of the directors with inadequate instruction in analytical, human relations, statistical, research, online retrieval, managerial, system analysis, and supervisory skills. These are the areas in which they apparently feel library schools need to improve the most. Note how many of these could contribute to improving the evaluation process: analytical, statistical, research, managerial, and system analysis skills.

McBurney came to a similar conclusion. Further, she suggested that library schools might emphasize academic-subject and foreign-language competency in their admissions requirement. ${ }^{7}$ Perhaps joint master's degree programs might also help.

Administrators did not agree that managerial and supervisory skills should be learned in library school, but they agreed those skills are not being taught there now. About as many directors felt these competencies should be learned on the job as felt they should be learned in library school. The ma-

TABLE 4

Skill AcQuisition in Library School, Ranked by Unmet Differential

\begin{tabular}{|c|c|c|c|}
\hline Skills & $\begin{array}{l}\text { Number of D } \\
\text { Skills Are } \\
\text { Acquired in } \\
\text { Library School }\end{array}$ & $\begin{array}{l}\text { tors Believing } \\
\text { Skills Should } \\
\text { Be Acquired in } \\
\text { Library School }\end{array}$ & $\begin{array}{l}\text { Unmet } \\
\text { Differ- } \\
\text { ential }\end{array}$ \\
\hline 1. Analytical skills & 8 & 58 & 50 \\
\hline 2. Human relations skills & 4 & 49 & 45 \\
\hline 3. Statistical skills & 6 & 50 & 44 \\
\hline 4. Research skills & 21 & 60 & 39 \\
\hline 5. Online retrieval skills & 30 & 69 & 39 \\
\hline 6. Managerial skills & 4 & 43 & 39 \\
\hline 7. System analysis skills & 13 & 50 & 37 \\
\hline 8. Supervisory skills & 4 & 41 & 37 \\
\hline 9. Knowledge of collection development & 45 & 73 & 28 \\
\hline 10. Knowledge of library issues & 47 & 72 & 25 \\
\hline 11. Computer programming skills & 9 & 26 & 17 \\
\hline 12. Knowledge of theories of organizing information & 55 & 72 & 17 \\
\hline 13. Basic knowledge of library automation & 59 & 75 & 16 \\
\hline 14. Knowledge of library history & 61 & 72 & 11 \\
\hline 15. Knowledge of specialized reference materials & 63 & 72 & 9 \\
\hline 16. Knowledge of general bibliography & 67 & 75 & 8 \\
\hline 17. Knowledge of general reference materials & 71 & 75 & 4 \\
\hline 18. Knowledge of a foreign language & 1 & 4 & 3 \\
\hline 19. Knowledge of an academic subject & 1 & 2 & 1 \\
\hline
\end{tabular}


jority felt they are learned on the job or at institutes and conferences after hiring.

The questions regarding where instruction is and should take place are of a different character than the previous ones. Whereas previous questions focused on the requirements of beginning librarian roles, these apply also to the needs of later role assignments. Educators who believe library schools should prepare librarians for middle-management assignments as well as the first month on the job might pay special attention to this section.

\section{Summary and Conclusion}

A library school must make choices regarding what to emphasize. The short time a school has with its students is too brief to teach everything its faculty might think important. One way to test whether the schools are making good decisions, from the perspective of library directors, is to compute a correlation coefficient between the competency importance and possession scores. When this was done, the correlation was .689, indicating that newly hired professionals generally possess skills and knowledge that the directors believe to be important to their roles. A few discrepancies showed up. Areas of greatest weakness, in order of severity, were: (1) analytical skills and (2) human relations skills. Improving instruction in those areas may call for reductions in others. Those in which competency possession was greater than required are prime candidates for reduction and were: (1) library history, (2) computer programming skills, (3) library issues, and (4) specialized reference materials.

No doubt many will disagree with one or more of these conclusions. For example, computer programming skills are ranked last in both importance and possession. Should instruction really be reduced? The respondent directors may have overestimated how much is occurring now. Moreover, they reported it as of the lowest priority for most position categories but third highest for the systems/computer service specialist. A little programming knowledge seems very satisfactory for all other categories, and the systems/computer heads rank programming instruction less important for these specialists than do the directors.

This aspect of the analysis is really more fruitful regarding what aspects should be increased than which might be reduced. The data propose increased instruction now in analytical and human relation skills and during the next five years, in online retrieval skills, system analysis skills, and library automation. In only one area, knowledge of general bibliography, was a declining need suggested. Are library schools to extend the length of their programs? If so, are research libraries prepared to increase salaries to justify the increased investment? Consider also that greater academic subject knowledge is expected in the future. Does that mean a double master's degree, one in library science and one in an academic subject? There is a slow movement in that direction now. Should library schools also encourage the development of more joint master's degree programs? Increases in the quantity of education probably will occur but better entry-level salaries will be required to sustain them.

\section{REFERENCES}

1. Association of Research Libraries, Education for the Research Library Professional, Minutes of the Ninety-Seventh Meeting, October 15-16, 1980, Arlington, Va. (Washington, D.C.: The Association, 1981), p.28-35.

2. Ibid., p.28-29.
3. Ibid., p.29.

4. Ibid.

5. Ibid.

6. Ibid., p.29-30.

7. Ibid., p. 30 . 